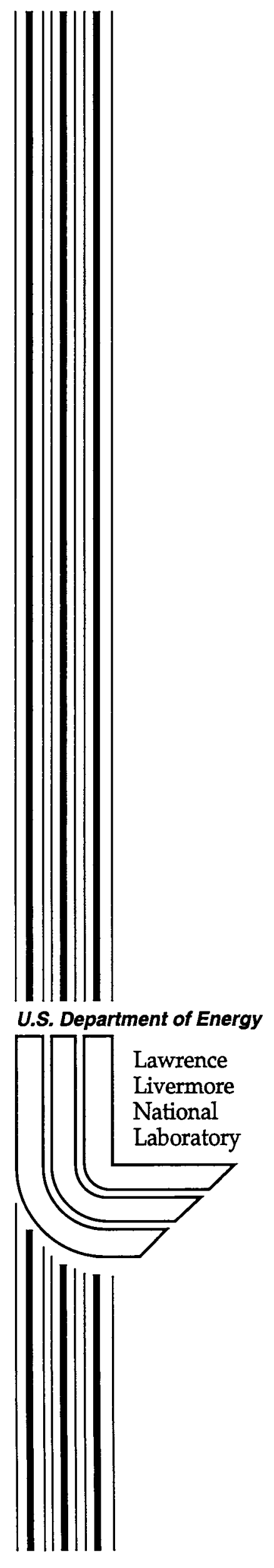

UCRL-ID-138838-REV-2

\title{
High-Efficiency Steam Electrolyzer
}

A.-Q. Pham, E. See, D. Lenz, P. Martin, R. Glass

July 3, 2002 


\section{DISCLAIMER}

This document was prepared as an account of work sponsored by an agency of the United States Government. Neither the United States Government nor the University of California nor any of their employees, makes any warranty, express or implied, or assumes any legal liability or responsibility for the accuracy, completeness, or usefulness of any information, apparatus, product, or process disclosed, or represents that its use would not infringe privately owned rights. Reference herein to any specific commercial product, process, or service by trade name, trademark, manufacturer, or otherwise, does not necessarily constitute or imply its endorsement, recommendation, or favoring by the United States Government or the University of California. The views and opinions of authors expressed herein do not necessarily state or reflect those of the United States Government or the University of California, and shall not be used for advertising or product endorsement purposes.

This work was performed under the auspices of the U. S. Department of Energy by the University of California, Lawrence Livermore National Laboratory under Contract No. W-7405-Eng-48.

This report has been reproduced directly from the best available copy.

Available electronically at http://www.doc.gov/bridge

Available for a processing fee to U.S. Department of Energy

And its contractors in paper from

U.S. Department of Energy

Office of Scientific and Technical Information

P.O. Box 62

Oak Ridge, TN 37831-0062

Telephone: (865) 576-8401

Facsimile: (865) 576-5728

E-mail: reports@adonis.osti.gov

Available for the sale to the public from

U.S. Department of Commerce

National Technical Information Service

5285 Port Royal Road

Springfield, VA 22161

Telephone: (800) 553-6847

Facsimile: (703) 605-6900

E-mail: orders@ntis.fedworld.gov

Online ordering: http://www.ntis.gov/ordering.htm

OR

Lawrence Livermore National Laboratory

Technical Information Department's Digital Library

http://www.llnl.gov/tid/Library.html 
This document contains no classified nor SUI:

Roviewed by:

\title{
HIGH-EFFICIENCY STEAM ELECTROLYZER
}

\author{
Ai-Quoc Pham, Ervin See, Dave Lenz, Peter Martin and Robert Glass \\ Lawrence Livermore National Laboratory \\ 7000 East Avenue, L-350, Livermore, CA 94550
}

\begin{abstract}
We are developing a novel high-efficiency, high-temperature steam electrolyzer. Although water or steam electrolysis is well known to be one of the cleanest ways to produce hydrogen, widespread utilization is hindered by high operational costs because of high electricity consumption. To decrease the electrical power input requirements in electrolysis, our approach uses natural gas as an anode depolarizer. This approach essentially replaces one unit of electricity with one equivalent-energy unit of natural gas at much lower cost. The direct use of natural gas on the electrolyzer enables very high system efficiency with respect to primary energy. Experiments performed on single cells have shown a voltage reduction as much as $1 \mathrm{~V}$ when compared to conventional electrolyzers. System efficiency has been estimated to be 50 to $80 \%$, depending on the electrolytic current density. During FY02, we have accomplished several major milestones, including the development of a metal-to-ceramic seal that withstands 150 psi differential, the fabrication of the electrolyzer tubes of up to 16 inches in length, the improvement of single tube performance and the demonstration of the first electrolyzer stack.
\end{abstract}




\section{Introduction}

Currently, most hydrogen demand is met by hydrogen production from fossil fuels, i.e., by steam reforming of natural gas and by coal gasification. However, most of these central plants are located in remote areas. The hydrogen produced must then be delivered to the users either by truck or via hydrogen pipelines. Because of the inherently low energy density of hydrogen, transportation by truck is not a viable option. Hydrogen delivery using pipelines is not costeffective either because of the high cost of the pipelines. Therefore, hydrogen production for a future hydrogen economy is likely to be accomplished using a distributed system where hydrogen is produced close to where it is consumed. A distributed hydrogen production system using small conventional steam-reforming reactors is not feasible because of the high cost and low efficiency of the reactors at small scales. More interesting approaches, such as autothermal reforming, micro-channel steam reforming as well as partial oxidation processes, are currently being pursued. However, these approaches are fairly complex, involving several additional steps, such as high-temperature shift, low-temperature shift, and preferential oxidation or hydrogen gas separation.

Hydrogen can be produced from water or steam electrolysis using much simpler technology. Because of the modularity of the electrolyzer, electrolysis can be done at a large central plant, at a refueling station, or even at home. In addition, electrolysis using renewable electricity offers the possibility of producing hydrogen without any greenhouse gas emissions. However, water electrolysis has not had a significant commercial impact because it has not been cost-effective.

The main drawback of conventional electrolyzers is the high electricity consumption. Electricity from the typical grid is known to be by far the most expensive form of energy. As a result, electrolytic hydrogen is more expensive than the steam-reformed hydrogen by a factor of at least two to three (Donitz 1980, Donitz 1985, Donitz 1990). Moreover, electricity is not a primary energy but must be produced using fossil fuels, nuclear fuels, or renewable energy. Considering the fact that production of electricity has an average efficiency of less than $40 \%$ with respect to primary energy, the overall efficiency of the electrolyzer in general is below $40 \%$ (Donitz 1990). In addition, less than $20 \%$ of the overall electricity production in the United States uses renewable energy. As a consequence, electrolysis using electricity from the grid is not a carbon-free process but actually involves the production and release of large amounts of greenhouse gases. From this viewpoint, conventional electrolysis is probably the worst hydrogen production technology in terms of greenhouse-gas emissions. On the other hand, electrolysis using exclusively renewable energy would have limited applications because it must be linked directly to a renewable energy source.

Recently, we have developed a new approach to reduce the electricity consumption in electrolyzers (Pham, 2000). Reduced electricity consumption was achieved by using natural gas to reduce the chemical potential difference across the electrolyzer cell. The concept is called Natural-Gas-Assisted Steam Electrolysis (NGASE). Although NGASE still involves carbon emissions because of the use of natural gas, the high efficiency and the simplicity of the system make it attractive as a hydrogen production technology for the transitional phase toward the hydrogen economy.

The goal of this project is to develop a prototype 3-5-kW-equivalent NGASE system for technology validation in 2006. 


\section{Concept}

In conventional steam electrolyzers, the gas supplied to the cathode side (where water is decomposed) is usually a mixture of steam and hydrogen, while the gas supplied to the anode side is usually air. At zero current, the system has an open-circuit voltage of 0.8 to $0.9 \mathrm{~V}$, depending on the hydrogen/steam ratio and on the operating temperature. In order to electrolyze water, a voltage that opposes and is larger in magnitude than the open-circuit voltage must be applied to pump oxygen from the steam side to the air side. Clearly, much of the electricity used, 60 to $70 \%$ of the total electrical power, is "wasted" by forcing the electrolyzer to operate against the high chemical potential gradient for oxygen.

To lower the open-circuit voltage, and thereby the electricity consumption, our approach is to replace air in the anode side with natural gas. The reducing character of natural gas helps to lower the chemical potential difference between the two sides of the electrolyzer. One can distinguish two different modes of operation: total oxidation and partial oxidation of natural gas. In the first case, natural gas is used in the anode side of the electrolyzer to burn out the oxygen resulting from the electrolysis, thus reducing or eliminating the potential difference across the electrolyzer membrane. The products of the reaction will be $\mathrm{CO}_{2}$ and steam. High fuel utilization is required. The role of natural gas is just to lower the chemical potential gradient, and therefore the electricity consumption. This mode replaces one unit of electrical energy by one equivalentenergy unit of natural gas at one fourth the cost. Thermodynamics limits the operational temperature for the total oxidation mode to temperatures lower than $800^{\circ} \mathrm{C}$. Above $800^{\circ} \mathrm{C}$, carbon monoxide becomes more stable and total oxidation is not possible.

In the second operational mode, an appropriate catalyst on the anode side promotes the partial oxidation of natural gas to $\mathrm{CO}$ and hydrogen. The resulting gas mixture, also called syngas, can be used in important industrial processes such as the synthesis of methanol and liquid fuels. Most importantly, $\mathrm{CO}$ can also be shifted to $\mathrm{CO}_{2}$ to yield additional hydrogen. In this process, hydrogen is produced at both sides of the steam electrolyzer. The overall reaction is equivalent to the steam reforming of natural gas. In contrast to steam-reforming reactors, the modular characteristics of the electrolyzer, together with the absence of the extensive heat exchangers, make it economically feasible to make small-scale hydrogen production units. However, the partial oxidation approach is much more complex than the total oxidation mode because it involves several additional reactor units, as described above for the steam-reforming process. In both cases, the key point of the approach is to use natural gas directly in the electrolyzer instead of using natural gas to make electricity at the central plant. The efficiency will be higher, and the carbon emissions will be lower than in conventional electrolysis.

We are currently focusing on the total oxidation mode because of its simplicity. One big advantage of the total oxidation mode is that the hydrogen produced does not need extensive separation beside the steam condensation. There is no contamination of hydrogen with carbon monoxide, which could damage and/or shorten the lifetime of the Proton Exchange Membrane Fuel Cells (PEMFCs). The hydrogen produced can be electrochemically pressurized, thus potentially eliminating the need for a hydrogen compressor.

\section{Summary of Previous Accomplishments}

We have demonstrated the proof-of-concept of the NGASE approach using single cells. A voltage reduction of $1 \mathrm{~V}$ was observed when methane was used in the anode side. The electricity consumption was estimated to be about one order of magnitude smaller than in 
conventional electrolyzers. Using thin film and novel catalyst materials, we demonstrated very high performance, up to $1 \mathrm{~A} \mathrm{~cm}^{2}$ at only $0.5 \mathrm{~V}$ at $700^{\circ} \mathrm{C}$. At $800^{\circ} \mathrm{C}$, cell current density was as high as $2.4 \mathrm{~A} / \mathrm{cm}^{2}$. For electrolyzer stack development, we selected the tubular approach since tubular structure has good mechanical integrity while enabling operation at high pressures.

We fabricated short electrolyzer tubes (up to 6 inches in length for the green tubes) and developed a coating technique that yielded high quality thin film electrolytes. We also developed a sealing technique. However, the seal failed at pressure differential greater than 80 psi and did not survive temperature cyclings.

\section{FY02 Accomplishments}

\section{Fabrication of electrolyzer tubes}

Making electrolyzer tubes is the single most important effort in the whole fabrication process of the NGASE stack. The approach adopted in the past was to use cold isostatic pressing. However, this technique was highly labor intensive and did not yield the tubes with the dimensions and porosity as needed. To make longer tubes with higher porosity, we developed a low-pressure injection molding technique. This technique is commonly used to fabricate ceramic and plastic tubings. The technique is readily accessible at the laboratory scale with minimal capital equipment investment. Figure 1 shows a picture of a 12 inch green tube. We have successfully fabricated green tubes up to 16 " in length. The length is now limited essentially by the furnace sizes only. After molding, the green tubes were partially sintered at intermediate temperatures. A thin film of yttria-stabilized-zirconia (YSZ) was then coated on the partially sintered tubes. Subsequently, the cathode was sprayed onto the YSZ film and the complete tube was then sintered at high temperatures. Some challenges remained to be addressed to keep the long tubes straight after sintering.

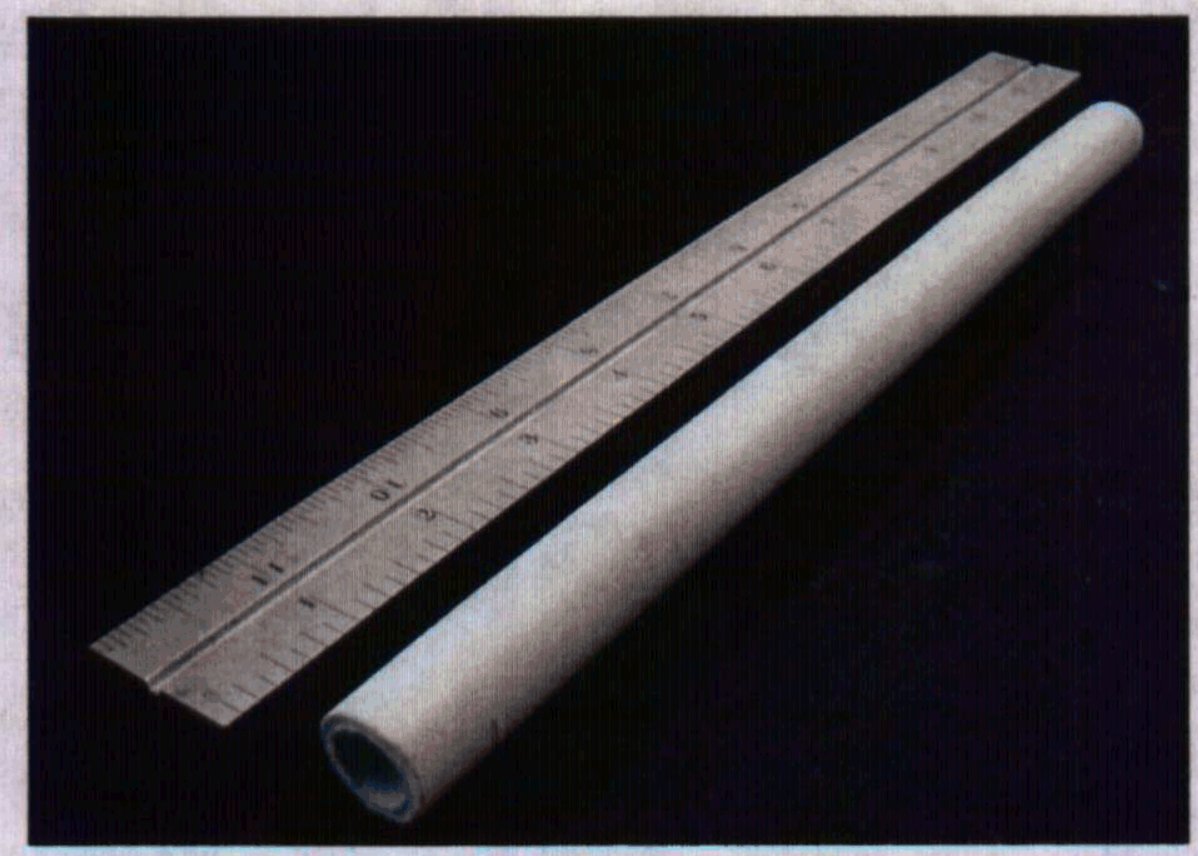

Figure 1: 12" long green tube, fabricated using the low pressure injection molding technique

\section{Performance improvement}

The electrochemical performance of the tubes fabricated using the cold isostatic pressing technique was reported last year to be fairly low. Using injection molded tube with improved electrodes, we achieved a significant increase in performance (see figure 2). 


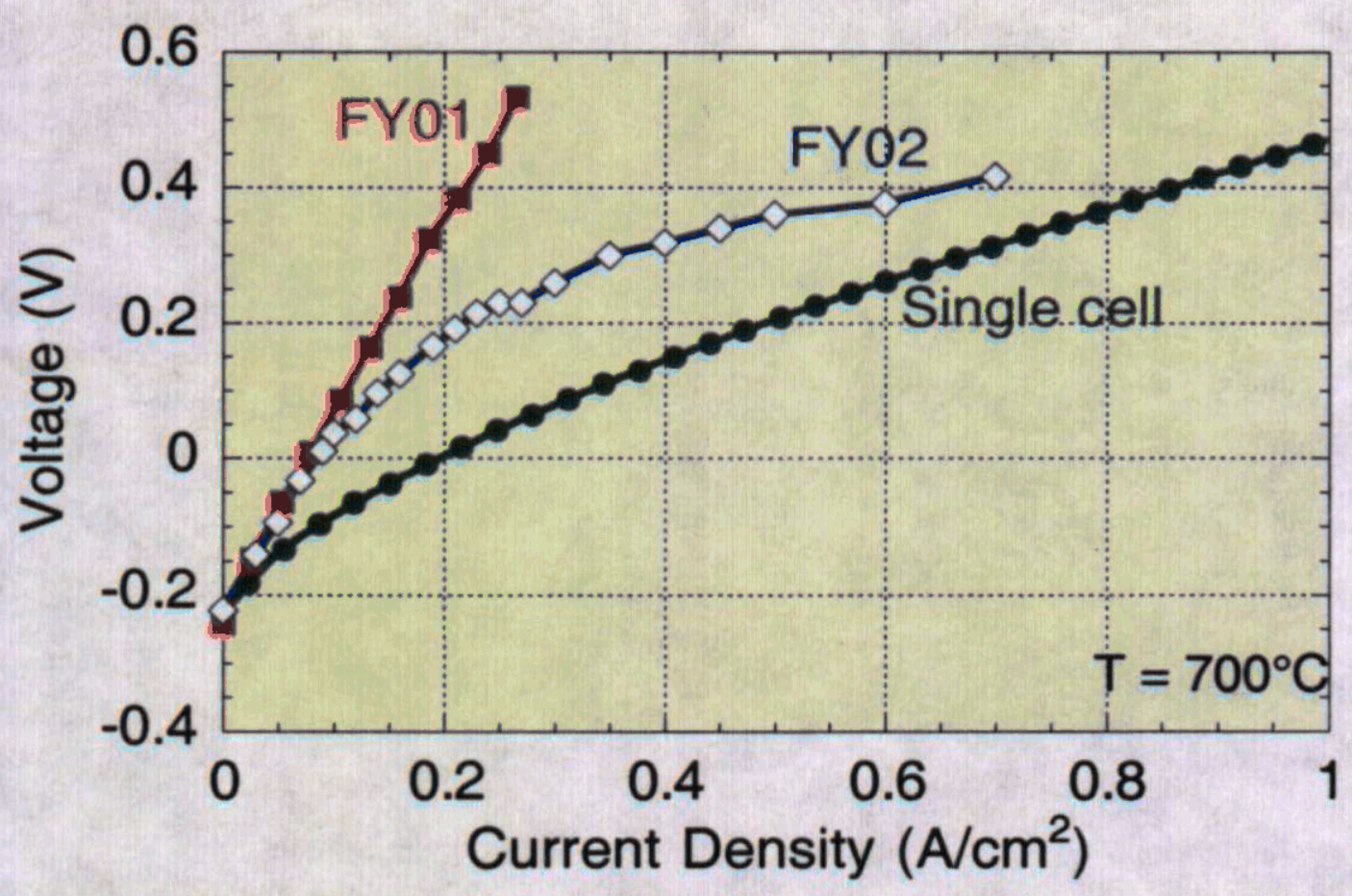

Figure 2: Electrochemical performance of single tube

\section{Seal Development}

Although the tubular design reduces significantly the issues typically encountered with sealing, there is still a need to seal the two ends of the tubes in order to avoid potential CO contamination and to enable operation with a pressure differential across the tube. In FY01, we reported a metal-to-ceramic seal using conventional brazing techniques. The seal withstood pressures up to $80 \mathrm{psi}$ and started to leak at higher pressure differential. During FY02, we redesigned the seal and successfully demonstrated an improved version of the metal-to-ceramic seal (figure 3). The seal has been tested up to 150 psi pressure differential and has been subjected to several rapid temperature cyclings. No performance degradation was observed.

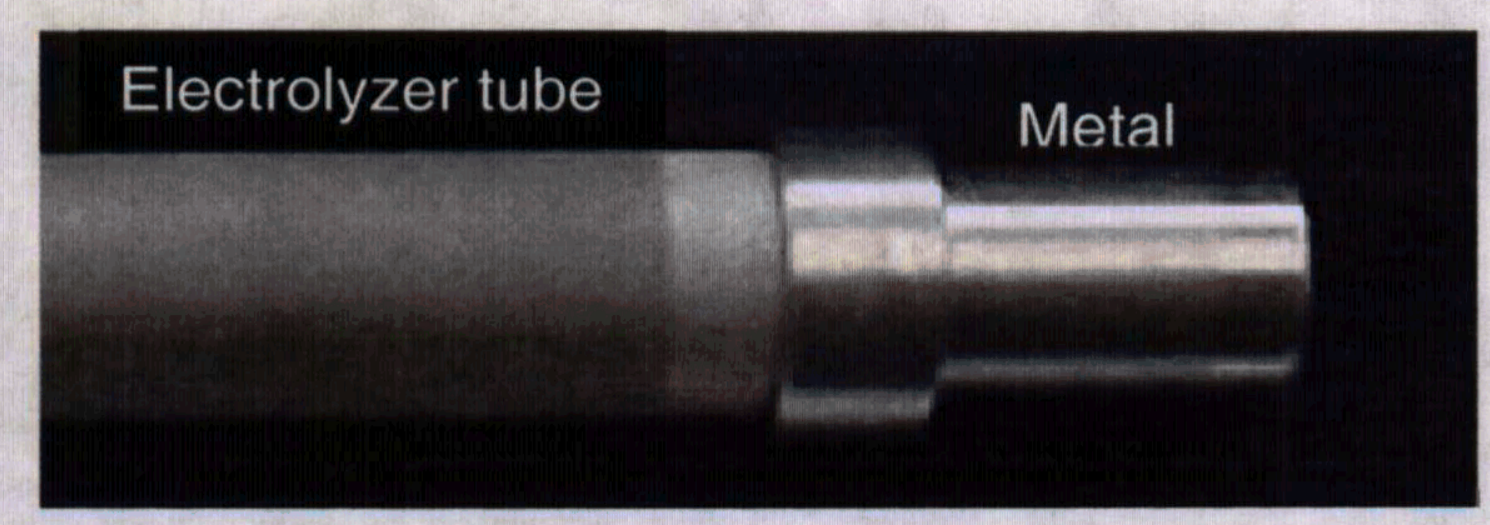

Figure 3: Picture of an electrolyzer tube sealed to a metal connector

\section{Stack development}

In FY01, we designed a tube-to-tube in series connection for the electrolyzer stack. The series connection was adopted because of the need to have high voltage and low current versus low voltage and high current. However, the series design required many brazing steps that turned out to be difficult to achieve because of mis-alignment and leakage problems. The tube-to-tube in series design was then abandoned. We are currently working on a new stack 
design that would preserve the desired characteristics of high voltage and low current while having only two seals at the two ends of the tubes

As a first step in the effort to scale up, we fabricated the first electrolyzer stack (figure 4). The stack was composed of four tubes connected in parallel. This first stack should serve as a prototype building block for larger stacks in the future. Figure 5 shows the I-V curve for the stack at an operating temperature of $750^{\circ} \mathrm{C}$. The operating pressure was 35 psi. Higher pressures could not be achieved because of leakage in the metal vessel. As seen in figure 5 , a current up to $100 \mathrm{amp}$ was passed through the electrolyzer stack, corresponding to a hydrogen production rate of $700 \mathrm{sccm}$ (STP), $75 \%$ of the project goal of $1000 \mathrm{sccm}$. The stack performance was lower than what would be expected from the measurement of single tubes. The difference could come from the resistive loss in the cables because of very high current in the stack. This observation suggests that a series design with lower current and higher voltage is more desirable. A new stack design is being developed.

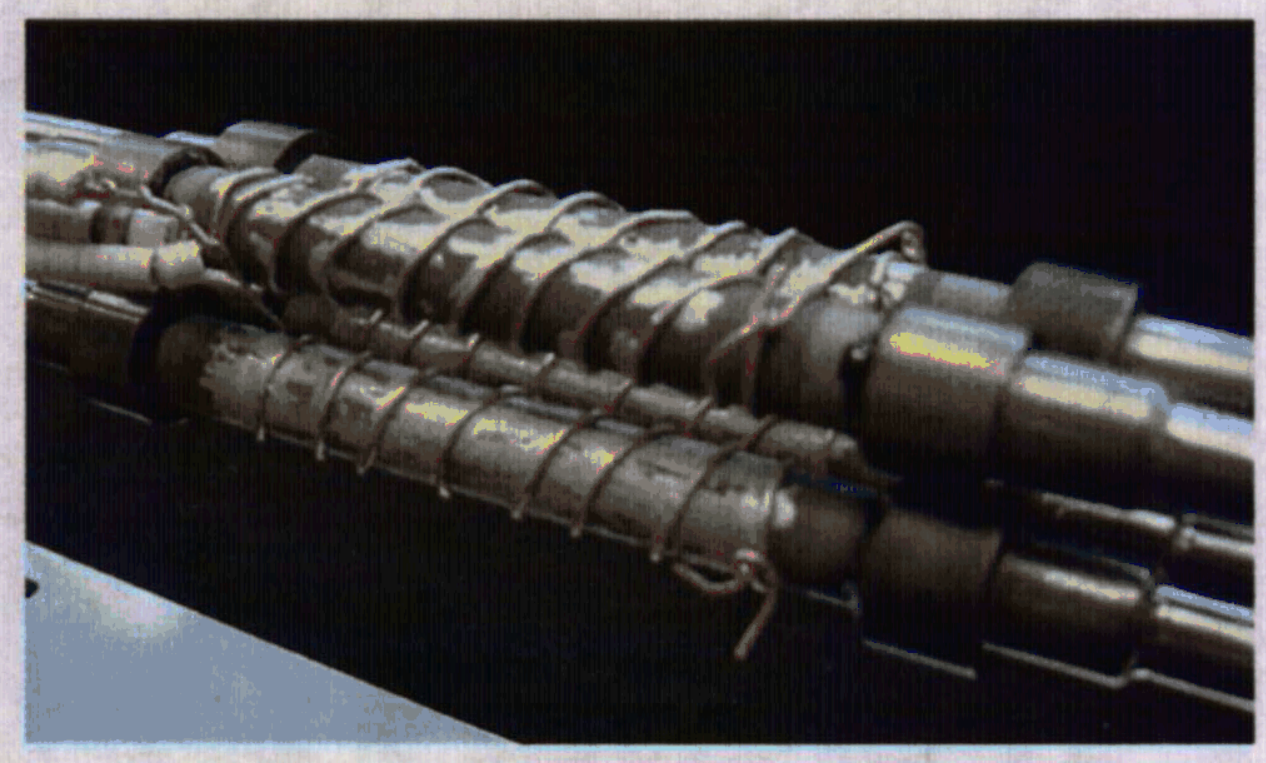

Figure 4: A 4-tube electrolyzer stack

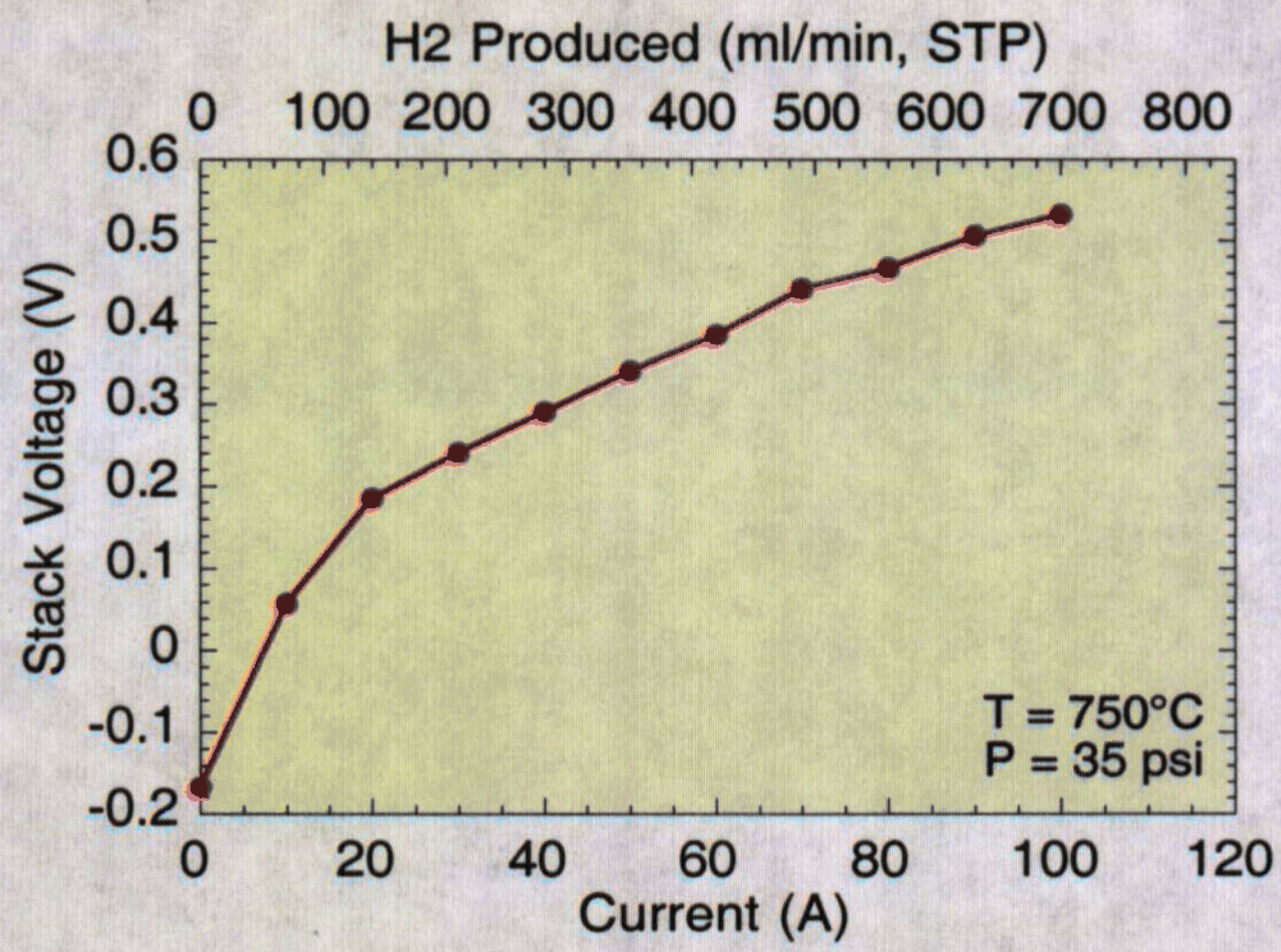

Figure 5: I-V curve of the electrolyzer stack 


\section{Conclusion and Future Work}

We have advanced considerably the development of the NGASE. Some major obstacles reported last year have been overcome. These include: the successful development of the lowpressure injection molding technique that enables the fabrication of green ceramic tube up to $16^{n}$ in length, the redesign of the metal-to-ceramic seal that withstands pressure differential up to $150 \mathrm{psi}$, the improvement of tube performance, and especially the first demonstration of an electrolyzer stack.

We will further improve the tube fabrication process in order to have tube performance close to that of single disks. Long-term stability will be evaluated. We will continue the system and process engineering to develop NGASE stacks. Our goal is to fully develop a NGASE prototype for technology validation in 2006. Solid Oxide Systems, LLC (SOX) (originally American Fuel Cells, LLC), a private start-up company, has recently negotiated an exclusive licensing of our technology. SOX will work with us through a CRADA to bring this technology to commercialization. In particular, SOX will provide the manufacturing support that is much needed for the fabrication of $\mathrm{kW}$ size systems.

\section{Acknowledgements}

This work was performed under the auspices of the U.S. Department of Energy by University of California Lawrence Livermore National Laboratory under contract No. W-7405-Eng-48.

\section{References}

Donitz, W., Schmidberger, R., Steinheil, E., Streicher, R., Int. J. Hydrogen Energy, 5,55 (1980). Donitz, W., and E. Erdle, Int. J. Hydrogen Energy, 10, 291 (1985).

Donitz, W., Erdle, E., Streicher, R., 1990. Electrochemical Hydrogen Technologies., Wendt, H., Editor. Elsevier. p 213.

Pham, A.Q., H. Wallman, R.S. Glass, US patent n6051125 (April, 2000). 